\title{
SUPERVIVENCIA PROLONGADA EN UN CASO DE TRASPLANTE BIPULMONAR POR FIBROTÓRAX SECUNDARIO A ESPOROTRICOSIS SISTÉMICA
}

\author{
GUTIÉRREZ BOLAÑOS JOHANN ${ }^{1}$, VARELA TABARES DIANA CRISTINA ${ }^{1}$, LONDOÑO VILLEGAS ALEJANDRO을 ORTEGA JARAMILLO \\ HÉCTOR ${ }^{2}$, RONCANCIO VILLAMIL GUSTAVO ${ }^{2}$
}

1. MEDICINA INTERNA, UNIVERSIDAD PONTIFICIA BOLIVARIANA, MEDELLÍN, COLOMBIA.

2. NEUMOLOGÍA, CLÍNICA CARDIOVID, MEDELLÍN, COLOMBIA.

3. ENFERMEDADES INFECCIOSAS, CLÍNICA CARDIOVID, MEDELLÍN, COLOMBIA.

\section{Introducción}

La esporotricosis es una micosis subaguda y crónica causada por el complejo de hongos Sporothrix schenckii. Tiene distribución mundial de predominio en áreas tropicales y subtropicales. El compromiso principalmente es cutáneo pero puede presentarse infección sistémica en casos aislados comprometiendo el pulmón. Describimos un caso de trasplante pulmonar exitoso secundario a esporotricosis sistémica.

\section{Caso clínico}

Hombre de 42 años quien presenta esporotricosis linfocutánea en 1998 con tratamiento efectivo. Dos años después presenta disnea progresiva (mMRC:4), tos productiva, fiebre episódica, sudoración nocturna y escalofríos. Se realiza una biopsia pulmonar transbronquial con evidencia de esporotricosis pulmonar que se trató con itraconozal. Estuvo libre de enfermedad por 8 años, con posterior empeoramiento de la función pulmonar, fibrotórax bilateral y falla hipoxémica. Se realizó biopsia pulmonar quirúrgica con evidencia de cuerpos asteroides, inflamación granulomatosa crónica sin necrosis caseificante y extensa fibrosis. Se ingresa a protocolo de trasplante sin encontrarse contraindicaciones y se procede a trasplante bipulmonar, del cual lleva 11 años de supervivencia (jun 2008) y con clase funcional NYHA-1.

Figuras 1 y 2: Radiografías antes y después del trasplante
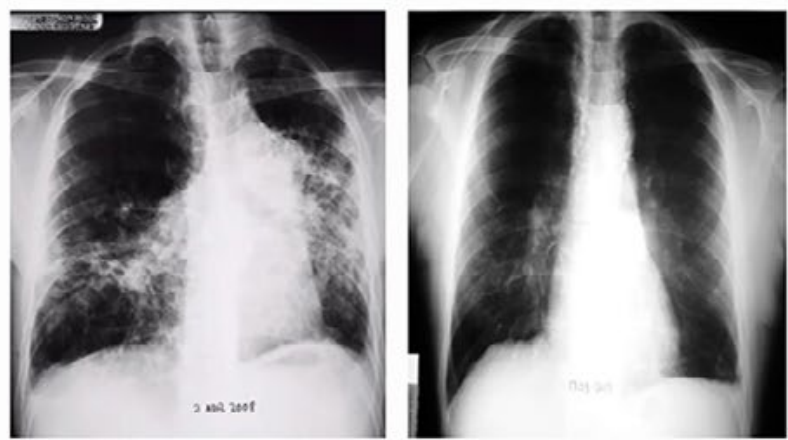

Figuras 3 y 4: Tomografia pulmonar y cuerpos asteroides
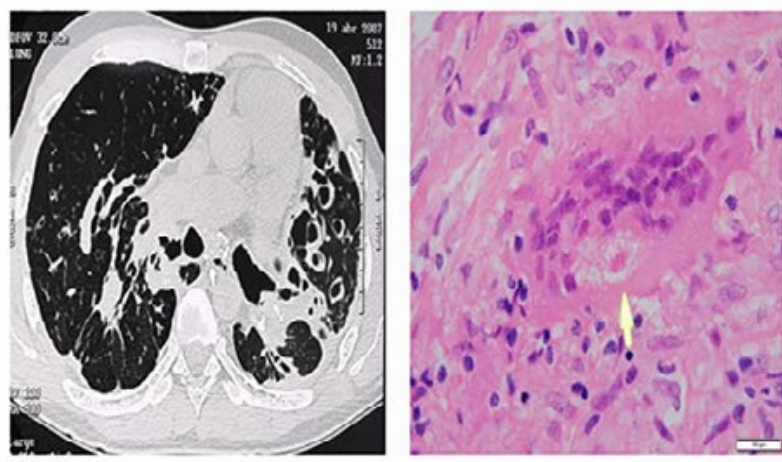

\section{Discusión}

La esporotricosis sistémica con compromiso pulmonar es una manifestación poco usual de la infección cutánea por S. schenkii que se presenta en menos del $2 \%$ de los casos. El curso clínico es crónico, con deterioro progresivo de la función pulmonar, fibrosis intersticial y síntomas constitucionales terminales. La respuesta a antifúngicos no es completamente efectiva y la infección recurre en el tiempo. Hay pocas series reportadas en la literatura de trasplante pulmonar secundario a esporotricosis, con tasas variables de supervivencia. Nuestro paciente fue traspantado sin complicaciones, con manejo inmunosupresor adecuado y sin episodios de reactivación sistémica de la infección. 